\title{
The Role of Uterine Artery Doppler Sonography in Predicting Pre-eclampsia at 14-20 Weeks of Gestation
}

\author{
Maysaa A. Chyad, Enas A. Azab, Mennatallah H.Shalaby, Ahmad A. Aly \\ Department of Radiodiagnosis \\ Faculty of Medicine - Ain Shams University \\ Corresponding author; Mobile: 01016262353; Email: maysaakubasi@yahoo.com
}

\begin{abstract}
Background: the introduction of Doppler technology has proved the first opportunity for repetitive, noninvasive hemodynamic monitoring in human pregnancy compared to other methods of maternal and fetal monitoring. Aim of the Work: this study aimed to predict usefulness of uterine artery Doppler in predicting pre-eclampsia and to study uterine artery Doppler waveforms at 14-20 weeks of gestation. Patients and Methods: this prospective study was carried out in the Radiodiagnosis Department Ain Shams University. This study included 33 pregnant women (between 14 to 20 weeks of pregnancy); they were chosen randomly from patients referred from maternal clinics, all were primigravida, single pregnancy during the period from June 2017 to December 2017. Results: regarding our results when RI index was used, sensitivity, specificity were $90.0 \%, 87.0 \%$ and when PI index was used sensitivity, specificity were $60.0 \%, 87.0 \%$. Conclusion: we can conclude that uterine artery Doppler between 14- 20 weeks of gestation is a simple rapid non-invasive procedure and it can be used as a reliable indicator for prediction of preeclampsia to use it as a screening test. Recommendations: we recommend other studies with a wide scale of population (large number) in more than one center; this will lead to increased surveillance and delivery in a well-equipped setup in high risk detected patient which is necessary to reduce the maternal and fetal complications.
\end{abstract}

Key words: uterine, artery, Doppler, solography, pre-eclampsia, gestation

\section{Introduction}

Pre-eclampsia is heterogeneous disorder with variable maternal and fetal manifestations (1). Pre-eclampsia complicates $3 \%-8 \%$ of pregnancies worldwide, overall 10 $15 \%$ of maternal deaths are associated with preeclampsia and eclampsia ${ }^{(2)}$.

Even in the era of modern obstetrics, pre-eclampsia remains as a major complication of pregnancy which can lead to significant incidences of maternal and neonatal mortality and morbidity. Despite advances in medical research, reliable screening test for prediction of these adverse complications still lacking (1). In the mother, pre-eclampsia may cause premature cardiovascular disease, such as chronic hypertension, ischemic heart disease and stroke later in life, while children born after preeclamptic pregnancies and who are relatively small at birth, have an increased risk of stroke, coronary heart disease and metabolic syndrome in adult life ${ }^{(\mathbf{1})}$. Pre-eclampsia is defined as the development of hypertension, proteinuria, or both, after 20 weeks in women with previously normal blood pressure ${ }^{(3)}$. It may be associated with many other signs and symptoms such as edema, visual disturbances, headacheand epigastric pain ${ }^{(4)}$.The fundamental cause of pre-eclampsia is thought to be the abnormal uteroplacental circulation resulting from the failure of second wave of trophoblastic invasion into spiral arterioles, this will result in increased resistance to flow within the uterine arteries and decreased plancental perfusion as well as due to imbalance between the prostacycline and thrombaxane A2 production ${ }^{(5)}$. The crucial issue to understand is that the prime mover of pre-eclampsia is abnormal placentation. Two common theories appear to be interlinked, ie, a genetic theory and an immunological theory ${ }^{(\boldsymbol{6})}$. Pre-eclampsia can be perceived as an impairment of the maternal immune system that prevents it from recognizing the feto-placental unit ${ }^{(7)}$. This concept has led to the idea of using Doppler assessment of uterine artery flow velocity waveform as a screening test for predicting preeclampsia ${ }^{(8)}$.Doppler examination of uterine arteries is a noninvasive tool that can be used to indirectly assess trophoblast development and uteroplacental perfusion ${ }^{(9)}$.Uterine artery Doppler sonography which is done during the second trimester can accurately predict preeclampsia, Resistance Index (RI), pulsatility index (PI) which are considered indirect measures of uteroplacental circulation ${ }^{(\mathbf{1 0})}$.

Aim of the Work: this study aimed to predict usefulness of uterine artery Doppler in predicting pre-eclampsia and to study uterine 
artery Doppler waveforms at 14-20 weeks of gestation.

\section{Patients and Methods:}

This prospective study was carried out in Radiodiagnosis Department Ain Shams University in period from June 2017 to December 2017. This study included 33 pregnant women (between 14 to 20 weeks of pregnancy) chosen randomly from patient referred from maternal clinics, all were primigravida, single pregnancy.

The uterine artery resistive index and pulsatility index was calculated between 14 to 20 weeks of pregnancy. The main uterine artery was located at the uterocervical junction close to the cross- over point of the uterine and external iliac arteries on both sides. RI $>0.7 \&$ $\mathrm{PI}>1.4$ was considered abnormal.The patient was explained in detail about the noninvasive nature of the procedure. Synthetic ultra-gel was applied over the abdomen to get a good acoustic coupling. All patients included in this study had a follow up blood pressure as a part of antenatal care in the Department of Gynecology and Obstetrics, Faculty of Medicine, Ain Shams University.

Transabdominal uterine artery Doppler was done by using GE ultrasound machine, curvilinear probe $(3.5 \mathrm{MHz})$ by localizing the uterine artery at uterocervical junction where it appeared to cross the external iliac artery.Good quality waveform was obtained by using an angle of insonation $<60^{\circ}$.

The variables analyzed were:

1. Resistance index (RI) was calculated using formula RI = Peak systolic velocity - Peak diastolic velocity/ Peak systolic velocity.

2. Pulsatility index (PI) will be calculated using formula. $\mathrm{PI}=$ Peak systolic velocity End diastolic velocity / Mean velocity, and both calculated automatically.

Subsequent development of preeclampsia can be predicted when resistive index is more than 0.7 and pulsality index is more than 1.4 (11).

\section{Inclusion criteria:}

1. Single pregnancy.

2. Second trimester pregnancy.

3. Primigravida.

\section{Exclusion criteria:}

1. Multiple pregnancies.

2. Congenital fetal anomalies.
3. Mothers who are already hypertensive.

4. If the patient could not be followed up till delivery for any reason.

5. Women with congenital uterine anomaly.

In semi recumbent position, the ultrasound transducer was placed in either the left or right iliac fossae of the abdomen, directed towards the lateral uterine walls and downwards into the pelvis, to obtain the sagittal section of the uterus and cervical canal. This was followed by the introduction of the color flow imaging to produce a color map of flow over the region. The probe was tilted sideways but still maintaining its medial angulation (lower paracervical area), till the uterine artery was visualized as it crosses the external iliac artery and originated from the internal iliac artery. The sample volume was placed $1 \mathrm{~cm}$ distal to the point of apparent cross over before any branching of the uterine arteries. These characters were used as the standard landmark for investigation of the uterine artery. Pulsed Doppler gate was placed at this location to obtain flow waveforms and when at least 3 consecutive consistent waveforms are produced, the image is frozen. The Doppler indices generated automatically from the machine were, the Pulsatility Index (PI), Resistance Index (RI) and S/D Ratio. Then we followed up the patients in the third trimester of this pregnancy by measuring their blood pressure in two different occasions during the day not less than $6 \mathrm{hr}$ apart and record the value. Statistical analysis:

Data were analyzed using Statistical Program for Social Science (SPSS) version 20.0. Quantitative data were expressed as mean \pm standard deviation (SD). Qualitative data were expressed as frequency and percentage.

\section{The following tests were done:}

- Independent-samples t-test of significance was used when comparing between two means.

- Chi-square $\left(\mathrm{X}^{2}\right)$ test of significance was used in order to compare proportions between two qualitative parameters.

- Receiver operating characteristic analysis was used to find out the overall predictivity of parameter in and to find out the sensitivity and specificity at this cut-off value. 
- Sensitivity $=($ true $+v e) /[($ true $+v e)$

+ (false - ve) $]$.

- Specificity $=($ true $-v e) /[($ true - ve $)$

$+($ false $+v e)]$.

- $\quad \mathrm{PPV}=($ true $+\mathrm{ve}) /[($ true $+\mathrm{ve})+$ (false $+\mathrm{ve})]$.

○ $\quad \mathrm{NPV}=($ true $-\mathrm{ve}) /[($ true $-\mathrm{ve})+$ (false-ve)].

- The confidence interval was set to $95 \%$ and the margin of error accepted was set to $5 \%$. So, the p-value was considered significant as the following:
- Probability (P-value)

- P-value $\leq 0.05$ was considered significant.

- P-value $\leq 0.001$ was considered as highly significant.

- P-value >0.05 was considered insignificant.

Results:

In this study 33 patients were examined, 10 developed pre-eclampsia and 23 patients did not developed pre-eclampsia (Table 1)

Table 1: Preeclampsia distribution of the studied group.

\begin{tabular}{|l|c|c|}
\hline \multicolumn{1}{|c|}{ Preeclampsia } & No. & \% \\
\hline \hline Yes & 10 & $30.3 \%$ \\
\hline No & 23 & $69.7 \%$ \\
\hline Total & 33 & $100 \%$ \\
\hline
\end{tabular}

This table showed that the preeclampsia was $30.3 \%$ ) and non-preeclampsia was $69.7 \%$. The right uterine artery Doppler parameters (RI and PI value) were registered in 29 patients. The left uterine artery Doppler parameter (RI and PI value) was registered in 32 patients. The missed patients we couldn't register their parameters of uterine artery Doppler because of obesity of the patient or they did operation on this side (Ovarian cysts and appendectomy).

Table 2: Relation between RI, PI and pre-eclampsia in the right and left uterine arteries.

\begin{tabular}{|c|c|c|c|c|}
\hline \multirow{2}{*}{ Uterine Artery } & \multicolumn{2}{|c|}{ Preeclampsia } & \multirow{2}{*}{$\begin{array}{l}\text { Chi- } \\
\text { square }\end{array}$} & \multirow{2}{*}{ p-value } \\
\hline & Yes & No & & \\
\hline Right Uterine Artery & $\mathrm{N}=9$ & $\mathrm{~N}=20$ & & \\
\hline $\begin{array}{l}\text { Resistive index }>\mathbf{0 . 7} \\
\text { Yes } \\
\text { No }\end{array}$ & $\begin{array}{l}7(77.8 \%) \\
2(22.2 \%)\end{array}$ & $\begin{array}{c}1(5 \%) \\
19(95 \%)\end{array}$ & 13.016 & $<0.001$ \\
\hline $\begin{array}{l}\text { Pulsatality index }>\mathbf{1 . 4} \\
\text { Yes } \\
\text { No }\end{array}$ & $\begin{array}{l}4(44.4 \%) \\
5(55.6 \%)\end{array}$ & $\begin{array}{c}1(5 \%) \\
19(95 \%)\end{array}$ & 4.286 & 0.038 \\
\hline Left Uterine Artery & $\mathrm{N}=9$ & $\mathrm{~N}=\mathbf{2 3}$ & & \\
\hline $\begin{array}{l}\text { Resistive index }>\mathbf{0 . 7} \\
\text { Yes } \\
\text { No }\end{array}$ & $\begin{array}{l}3(33.3 \%) \\
6(66.7 \%)\end{array}$ & $\begin{array}{c}2(8.7 \%) \\
21(91.3 \%)\end{array}$ & 3.774 & 0.046 \\
\hline $\begin{array}{l}\text { Pulsatality index }>\mathbf{1 . 4} \\
\text { Yes } \\
\text { No } \\
\end{array}$ & $\begin{array}{l}3(33.3 \%) \\
6(66.7 \%) \\
\end{array}$ & $\begin{array}{c}2(8.7 \%) \\
21(91.3 \%)\end{array}$ & 3.774 & 0.046 \\
\hline
\end{tabular}

This table showed statistically significant difference between preeclampsia and nonpreeclampsia according to level of uterine artery RI and PI in the right and left sides.

Table 3: Comparison between preeclampsia and non-preeclampsia according to mean of uterine artery right and left. 


\begin{tabular}{|c|c|c|c|c|}
\hline \multirow{2}{*}{ Uterine Artery } & \multicolumn{2}{|c|}{ Preeclampsia } & \multirow{2}{*}{ t-test } & \multirow{2}{*}{ p-value } \\
\hline & Yes & No & & \\
\hline Right Uterine Artery & $\mathrm{N}=9$ & $\mathrm{~N}=\mathbf{2 0}$ & & \\
\hline $\begin{array}{l}\text { Mean of Resistive Index } \\
\text { Mean } \pm \text { SD } \\
\text { Range }\end{array}$ & $\begin{array}{c}0.71 \pm 0.06 \\
0.61-0.78\end{array}$ & $\begin{array}{c}0.57 \pm 0.09 \\
0.4-0.78\end{array}$ & 16.613 & $<0.001$ \\
\hline $\begin{array}{l}\text { Mean of Pulsatality index } \\
\text { Mean } \pm \text { SD } \\
\text { Range } \\
\end{array}$ & $\begin{array}{c}1.55 \pm 0.43 \\
1.02-2.45\end{array}$ & $\begin{array}{c}0.94 \pm 0.23 \\
0.52-1.31\end{array}$ & 25.259 & $<0.001$ \\
\hline Left Uterine Artery & $\mathbf{N}=9$ & $\mathrm{~N}=\mathbf{2 3}$ & & \\
\hline $\begin{array}{l}\text { Mean of Resistive Index } \\
\text { Mean } \pm \text { SD } \\
\text { Range }\end{array}$ & $\begin{array}{c}0.70 \pm 0.16 \\
0.39-0.93\end{array}$ & $\begin{array}{c}0.58 \pm 0.09 \\
0.42-0.77\end{array}$ & 6.693 & 0.015 \\
\hline $\begin{array}{l}\text { Mean of Pulsatality index } \\
\text { Mean } \pm \text { SD } \\
\text { Range }\end{array}$ & $\begin{array}{c}1.34 \pm 0.58 \\
0.51-2.43\end{array}$ & $\begin{array}{c}0.98 \pm 0.27 \\
0.61-1.58\end{array}$ & 5.905 & 0.021 \\
\hline
\end{tabular}

This table showed statistically significant difference between preeclampsia and nonpreeclampsia according to mean of uterine artery right and left.

Table 4: Comparison between preeclampsia and non-preeclampsia according to level of uterine arteries.

\begin{tabular}{|c|c|c|c|c|}
\hline \multirow{2}{*}{ Uterine Artery } & \multicolumn{2}{|c|}{ Preeclampsia } & \multirow{2}{*}{ Chi-square } & \multirow{2}{*}{ p-value } \\
\hline & Yes $(\mathrm{N}=10)$ & No $(\mathrm{N}=23)$ & & \\
\hline $\begin{array}{l}\text { Resistive index }>\mathbf{0 . 7} \\
\text { Yes } \\
\text { No }\end{array}$ & $\begin{array}{l}9(90.0 \%) \\
1(10.0 \%)\end{array}$ & $\begin{array}{c}3(13.0 \%) \\
20(87.0 \%)\end{array}$ & 17.837 & $<0.001$ \\
\hline $\begin{array}{l}\text { Pulsatality index }>\mathbf{1 . 4} \\
\text { Yes } \\
\text { No }\end{array}$ & $\begin{array}{l}6(60 \%) \\
4(40 \%)\end{array}$ & $\begin{array}{c}3(13 \%) \\
20(87 \%)\end{array}$ & 5.561 & 0.018 \\
\hline
\end{tabular}

This table showed highly statistically significant difference between preeclampsia and nonpreeclampsia according to level of uterine artery Doppler parameter (RI and PI value).

Table 5: Comparison between preeclampsia and non-preeclampsia according to mean of uterine artery.

\begin{tabular}{||l|c|c|c|c||}
\hline \multirow{2}{*}{ Mean of Uterine Artery } & \multicolumn{2}{|c|}{ Preeclampsia } & \multirow{2}{*}{ t-test } & \multirow{2}{*}{ p-value } \\
\cline { 2 - 3 } & Yes (N=10) & No (N=23) & & \\
\hline \hline Mean of Resistive Index & & & & \\
$\quad$ Mean \pm SD & $0.77 \pm 0.07$ & $0.60 \pm 0.09$ & \multirow{2}{*}{26.807} & $<0.001$ \\
$\quad$ Range & $0.67-0.93$ & $0.46-0.78$ & & \\
Mean of Pulsatality index & & & & \\
$\quad$ Mean $\pm S D$ & $1.70 \pm 0.50$ & $1.02 \pm 0.26$ & \multirow{2}{*}{26.668} & $<0.001$ \\
$\quad$ Range & $0.82-2.45$ & $0.62-1.58$ & & \\
\hline
\end{tabular}

This table showed highly statistically significant difference between preeclampsia and nonpreeclampsia according to mean of uterine artery.

Table 6: Diagnostic Performance of uterine artery in Discrimination of preeclampsia and non-preeclampsia right and left.

\begin{tabular}{||l|l|l|l|l|l|l|}
\hline Uterine Artery & Preeclampsia & Sens. & Spec. & PPV & NPV & AUC \\
\hline
\end{tabular}




\begin{tabular}{|c|c|c|c|c|c|c|c|}
\hline & Yes & No & & & & & \\
\hline Right Uterine Artery & $\mathrm{N}=9$ & $\mathrm{~N}=20$ & & & & & \\
\hline $\begin{array}{l}\text { Resistive index }>\mathbf{0 . 7} \\
\text { Yes } \\
\text { No }\end{array}$ & $\begin{array}{l}7(77.8 \%) \\
2(22.2 \%)\end{array}$ & $\begin{array}{c}1(5 \%) \\
19(95 \%)\end{array}$ & $77.8 \%$ & $95.0 \%$ & $87.5 \%$ & $90.5 \%$ & $89.7 \%$ \\
\hline $\begin{array}{l}\text { Pulsatality index }>1.4 \\
\text { Yes } \\
\text { No }\end{array}$ & $\begin{array}{l}4(44.4 \%) \\
5(55.6 \%)\end{array}$ & $\begin{array}{c}1(5 \%) \\
19(95 \%)\end{array}$ & $44.4 \%$ & $95.0 \%$ & $80.0 \%$ & $79.2 \%$ & $79.3 \%$ \\
\hline Left Uterine Artery & $\mathrm{N}=9$ & $\mathrm{~N}=23$ & & & & & \\
\hline $\begin{array}{l}\text { Resistive index }>\mathbf{0 . 7} \\
\text { Yes } \\
\text { No }\end{array}$ & $\begin{array}{l}3(33.3 \%) \\
6(66.7 \%)\end{array}$ & $\begin{array}{c}2(8.7 \%) \\
21(91.3 \%)\end{array}$ & $33.3 \%$ & $91.3 \%$ & $60.0 \%$ & $77.8 \%$ & $75.0 \%$ \\
\hline $\begin{array}{l}\text { Pulsatality index }>1.4 \\
\text { Yes } \\
\text { No }\end{array}$ & $\begin{array}{l}3(33.3 \%) \\
6(66.7 \%)\end{array}$ & $\begin{array}{c}2(8.7 \%) \\
21(91.3 \%)\end{array}$ & $33.3 \%$ & $91.3 \%$ & $60.0 \%$ & $77.8 \%$ & $75.0 \%$ \\
\hline
\end{tabular}

* Sensitivity of $77.8 \%$ specificity of $95 \%$ positive predictive value of $87.5 \%$, negative predictive value of $90.5 \%$ with diagnostic accuracy of $89.7 \%$ of right uterine artery "resistive index $>0.7$ ".

* Sensitivity of $44.4 \%$ specificity of $95 \%$ positive predictive value of $80 \%$, negative predictive value of $79.2 \%$ with diagnostic accuracy of $79.3 \%$ of right uterine artery "Pulsatality index $>1.4$ ".

* Sensitivity of $33.3 \%$ specificity of $91.3 \%$ positive predictive value of $60 \%$, negative predictive value of $77.8 \%$ with diagnostic accuracy of $75 \%$ of left uterine artery "Resistive index $>0.7$ ".

* Sensitivity of $33.3 \%$ specificity of $91.3 \%$ positive predictive value of $60 \%$, negative predictive value of $77.8 \%$ with diagnostic accuracy of $75 \%$ of right uterine artery "Pulsatality index $>1.4$ ".

Table 7: Diagnostic performance of uterine artery in discrimination of preeclampsia and non-preeclampsia.

\begin{tabular}{|c|c|c|c|c|c|c|c|}
\hline \multirow[b]{2}{*}{ Uterine Artery } & \multicolumn{2}{|c|}{ Preeclampsia } & \multirow[b]{2}{*}{ Sens. } & \multirow[b]{2}{*}{ Spec. } & \multirow[b]{2}{*}{ PPV } & \multirow[b]{2}{*}{ NPV } & \multirow[b]{2}{*}{ AUC } \\
\hline & $\begin{array}{c}\text { Yes } \\
(\mathrm{N}=10)\end{array}$ & No $(\mathbf{N}=23)$ & & & & & \\
\hline $\begin{array}{l}\text { Resistive index }>\mathbf{0 . 7} \\
\text { Yes } \\
\text { No }\end{array}$ & $\begin{array}{l}9(90.0 \%) \\
1(10.0 \%)\end{array}$ & $\begin{array}{c}3(13.0 \%) \\
20(87.0 \%)\end{array}$ & $90.0 \%$ & $87.0 \%$ & $75.0 \%$ & $95.2 \%$ & $87.9 \%$ \\
\hline $\begin{array}{l}\text { Pulsatality index }>1.4 \\
\text { Yes } \\
\text { No }\end{array}$ & $\begin{array}{l}6(60 \%) \\
4(40 \%)\end{array}$ & $\begin{array}{c}3(13 \%) \\
20(87 \%)\end{array}$ & $60.0 \%$ & $87.0 \%$ & $66.7 \%$ & $83.3 \%$ & $78.8 \%$ \\
\hline
\end{tabular}

* Sensitivity of $90 \%$ specificity of $87 \%$ positive predictive value of $75 \%$, negative predictive value of $95.2 \%$ with diagnostic accuracy of $87.9 \%$ of uterine artery "Resistive index $>0.7$ ".

* Sensitivity of $60 \%$ specificity of $87 \%$ positive predictive value of $66.7 \%$, negative predictive value of $83.3 \%$ with diagnostic accuracy of $78.8 \%$ of uterine artery "Pulsatality index $>1.4$ ".

\section{History:}

\section{Case 1}

A pregnant lady, 17 weeks +2 days of gestation, normotensive, no history of diabetes or hypertension. 


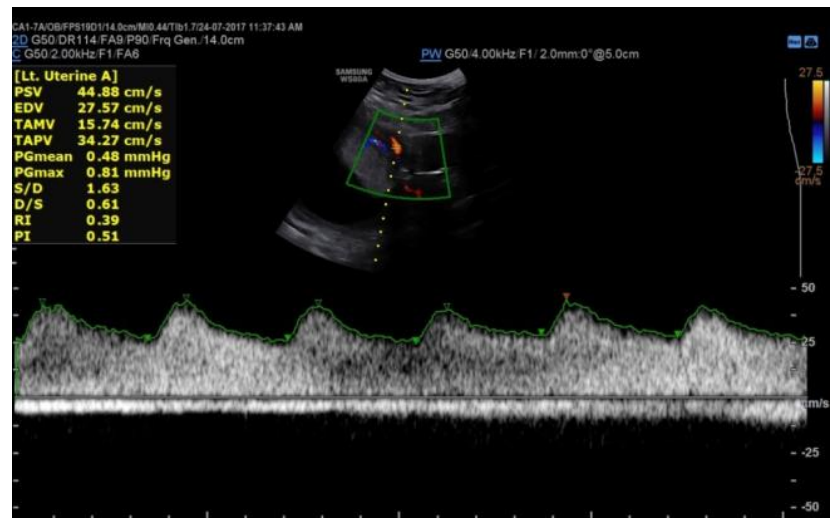

\section{Finding:}

The left uterine artery Doppler flow wave indices were:

RI 0.39

PI 0.51

Follow up:

Patient followed up in the third trimester for blood pressure measurement in the $33 \mathrm{wks}$, her blood pressure was 120/80 mmhg.

\section{Conclusion:}

The patient did not develop pre eclampsia.

\section{Case 2}

\section{History:}

A pregnant lady, 20 weeks of gestation, normotensive, no history of diabetes or hypertension.

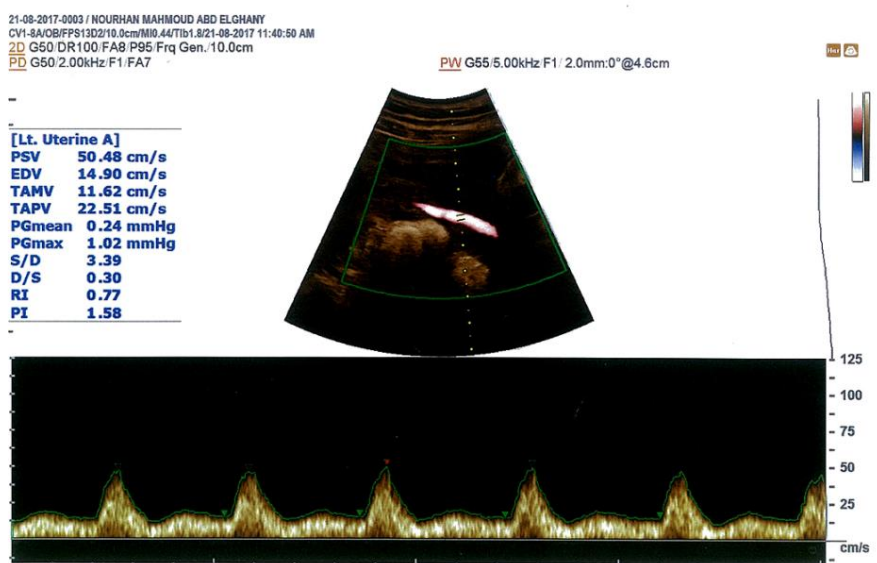

Finding:

The left uterine artery Doppler flow wave indices were:

RI 0.77

PI 1.58

Follow up:

Patient followed up in the third trimester for blood pressure measurement in the $34 \mathrm{wks}$, her blood pressure was 150/100 mmhg.

\section{Conclusion:}

The patient developed pre eclampsia at the third trimester

\section{Discussion:}

Accurate early identification of women at risk of preeclampsia could not only dramatically reduce the costs of antenatal care by enabling the identification and close surveillance of women with at-risk pregnancies, but also lead to improved management of hypertensive disorders in later life ${ }^{(\mathbf{1 2})}$. There are few data regarding the uteroplacental circulation Doppler pattern during the first and early second trimester of pregnancy ${ }^{(13)}$.The period $14-20$ weeks was chosen to perform the uterine Doppler evaluation because the routine scan for nuchal translucency and early second trimester anatomical assessment was already scheduled at this time of gestation in our population and placental implantation is completed by $14-18$ weeks ${ }^{(14)}$. The study of Polat et al. ${ }^{(15)}$ showed significant hemodynamic changes in uterine artery Doppler assessment during the 14 to 20 weeks of gestation; these hemodynamic 
changes were evident during the second trimester likely reflecting a time correlation between the intervillous circulation and marked changes in the umbilical and fetal circulations at this time of pregnancy. At this stage they supposed that transabdominal uterine examination may have technical problems because the uterus is not large enough and the full bladder technique is necessary to perform the Doppler examination. Consequently, the distended bladder may cause an alteration in blood flow in small arteries ${ }^{(15)}$. By using the transvaginal route, the probe is located closer to the uterine artery, the angle of insonation is usually closer to zero degree and the wave forms obtained have better definition ${ }^{(\mathbf{1 6})}$. In our study, transvaginal examination was done for just one patient, because the patients prefer transabdominal route than the transvaginal in early pregnancy, they afraid from bleeding and abortion.

In past decades, the prediction of preeclampsia has been attempted by using several maternal assessment methods; in this respect, Doppler flow studies of the uteroplacental circulation have been extensively performed, since they are easy, inexpensive, non-invasive and can be done in early pregnancy (17). However, Doppler ultrasound examination of the uteroplacental circulation has provided conflicting results when employed as a screening test for pre-eclampsia or any other hypertensive disorder of pregnancy ${ }^{(\mathbf{1 8})}$. The presentation of data on uteroplacental circulation by means of the study of arcuate arteries with Doppler velocimetry, showed that the diastolic notch of uterine arteries at the second and third trimesters of gestation, was related to the increase in uteroplacental vascular resistance, IUGR and hypertension (19). Impedance to blood flow in the uterine artery may increase in pregnancy complicated by hypertension when uterine artery Systole /Diastole ratio more than 2.6 during third trimester the birth weight at delivery was lower than normal ${ }^{(15)}$. Impaired uterine artery flow velocity can be identified by persistent abnormal index, persistent notch and significant difference between the indices in the two vessels ${ }^{(20)}$. The results of some of studies done in the past were comparable to our study and had similar results as we conclude.

Our study results are in line with the study done by Bhattacharyya et al. ${ }^{(21)}$ at their center from August 2007 to July 2008 involved
179 patients and they showed that Doppler velocimetry of uterine artery in the second trimester pregnancy can be used as a reliable screening test for prediction of preeclampsia, these women were categorized into high risk and low risk groups according to the risk factors, $52(29.05 \%)$ and $127(70.95 \%)$ were in high risk and low risk groups respectively, in low risk group which was similar to our study group,10 women developed preeclampsia, uterine artery velocimetry showed increased RI (>0.6) in 13 women $(10.24 \%)$ and among them, seven developed preeclampsia, notching was not seen in any of them, therefore, the sensitivity, specificity, PPV and NPV of abnormal uterine artery velocimetry were $70.0 \%, 94.87 \%, 53.84 \%$ and $97.37 \%$, respectively.

Cnossen et al. ${ }^{(22)}$ did a systemic review by variable meta-analysis of 74 studies of preeclampsia and they found that abnormal uterine artery waveforms were better predictor of preeclampsia. The total number of women was 79 547 , of whom 2498 were found to have preeclampsia; samples varied in size from 28 to 16 806 women (check the no), when RI index was used, sensitivity, specificity, positive predictive value, negative predictive value $51 \%, 87 \%$, $40 \%, 57 \%$ respectively and when PI index was used, sensitivity, specificity, positive predictive value, negative predictive value $39 \%, 78 \%$, $18 \%, 78 \%$ respectively

Costa et al. (23) included 45 women without a history of chronic (what do you mean by chronic gestation), gestational or gynecologic diseases, the sensitivity in the detection of preeclampsia was $100 \%$, but the specificity was $62.5 \%$ and $60.6 \%$ respectively, resulting in a low PPV.

Katie et al. ${ }^{(24)}$ described the changes in mean uterine artery RI and bilateral uterine artery notches between 20 and 24 weeks of gestation and its outcome was done; they concluded that 20 weeks are the most appropriate gestation in the second trimester to perform uterine artery Doppler.

Our study results are comparable to a

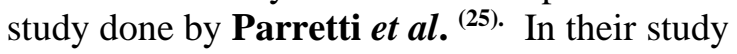
the total population was 108 women 36 from them developed pre-eclampsia in the third trimester using of an individual longitudinal flow pattern indicator resulted in improving accuracy in the prediction of pre-eclampsia as compared with the traditional cross-sectional, the mean $\mathrm{RI}$ is equal or more than 0.58 , the final 
result of the sensitivity, specificity, positive predictive value, negative predictive value were $77.8 \%, 67.6 \%, 44.4 \%, 90.1 \%$, respectively.

Since both the longitudinal flow pattern indicator and the longitudinal model showed a high performance in predicting pre eclampsia in women with risk factors for impaired placentation, they might be used to identify a high risk population in which preventive measures and/or the therapeutic options might be tested ${ }^{(26)}$.

Dehghani-firouzabadi et al. ${ }^{(1)}$ in their observational study from October 2011October 2012 involved 456 pregnant women of 14-16 weeks of gestation where Doppler study was done and they showed that Resistive Index $(<0.69)$ was observed in 429 patients, who had normal pregnancy outcome, whereas 36 women had RI >0.69 had complications of preeclampsia. The RI can be used to predict preeclampsia, total number of 27 patients showed abnormal uterine artery Doppler finding to develop preeclampsia 23 pregnancies $(85.2 \%)$ developed preeclampsia RI more than 0.7 and only 4 of them $(14.8 \%)$ had $\mathrm{RI}<0.7$ ( $\mathrm{P}=0.001)$, $26(96.3 \%)$ of patients who had RI>0.69 developed preeclampsia and only 1 patient (3.7\%) with $\mathrm{RI}<0.69$ developed preeclampsia.

Our study results are almost in line with study done by Afrakhteh et al. ${ }^{(27)}$. Two hundred and five pregnant women were able to complete their study and the final analyses in predicting sensitivity, specificity, positive predictive value, negative predictive value for resistive index were $77.2 \%, 89.6 \%, 47.2 \%$, $97 \%$ respectively. When PI used the value of sensitivity, specificity, positive predictive value, negative predictive were $48.8 \%$, $90.7 \%, 58 \%, 86.9 \%$ respectively; however when PI index was used alone the sensitivity was less than RI alone. So RI in second trimester was more sensitive in predicting preeclampsia than PI.

Our study results are consistent with the study of Nagar et al. ${ }^{(28)}$ where there was out of 500 patients, 110 patients had abnormal Doppler among them, 70 patients had abnormal uterine artery Doppler. When uterine artery was abnormal (30 patients), 20 patients had preeclampsia, 10 patients had pregnancyinduced hypertension (PIH), RI > 0.69 had sensitivity of $40 \%$ and specificity was $94.77 \%$, PPV $28.56 \%$, NPV $96.77 \%$.

There was no widely accepted or accurate method for the early prediction of pre- eclampsia, the present data presented by our results demonstrated a strong relationship between second-trimester uterine artery Doppler indices and the subsequent development of preterm pre-eclampsia. Even though uterine Doppler imaging may not fulfill the prerequisites for a valid screening test, it may be invaluable in triaging women for increased surveillance.

Studies of Parretti et al. (25), Melchiorre et al. ${ }^{(12)}$, Dehghani firouzabadi $e t$ al. ${ }^{(1)}$ used RI as main index in their study to determine the adverse outcomes of pregnancy, On the other hand, the value of specificity to detect adverse outcome was higher when RI, PI and bilateral notch values were combined.

We conducted this prospective study at our institute mainly consisting of urban population, in this study the uterine artery Doppler velocitometry was done in the second trimester, the RI and PI was calculated and used for analysis. Our results demonstrated lower impedance in the uterine artery of normal outcome pregnancies than in the complicated cases, suggesting that lack of normal uteroplacental circulation at this early stage of pregnancy may predict the later development of some pregnancy complications. In our study when RI index was used, sensitivity, specificity, positive predictive value, negative predictive value and diagnostic accuracy were $90.0 \%, 87.0 \%, 75.0 \%, 95.2 \%, 87.9 \%$ respectively and p value was calculated and it is significant which showed that RI index can be reliably used for screening for prediction of preeclampsia.

When PI index was used sensitivity, specificity, positive predictive value, negative predictive value diagnostic accuracy were $60.0 \%, \quad 87.0 \%, 66.7 \%, 83.3 \%, \quad 78.8 \%$ respectively and $\mathrm{p}$ value was calculated and it is significant which showed that PI index can be reliably to be used for prediction of preeclampsia.This suggested the valuable role of second trimester's uterine Doppler sonography in screening complicated pregnancy.

Our study detected abnormal uterine artery Doppler indices (High RI and PI) between 14 to 20 weeks of pregnancy, we can identify women at risk for development of preeclampsia; also this study demonstrated the feasibility of Doppler assessment of uterine arteries into the routine scan.

Conclusion: 
We can conclude that uterine artery Doppler between 14-20 weeks of gestation is a simple rapid non-invasive procedure and it can be used as a reliable indicator for prediction of preeclampsia to use it as a screening test.

\section{Recommendations:}

We recommend another studies with a wide scale of population (large number) in more than one center this will lead to increased surveillance and delivery in a well-equipped setup in high risk detected patient which is necessary to reduce the maternal and fetal complications.

References:

1.Dehghani-firouzabadi R, Saedeh $A$ and Reza NM (2013): Uterine artery Doppler sonography in predicting preeclampsia and IUGR at 14-16 week gestation. World Applied Sciences Journal, 22(2):197-201.

2.Uzan J, Carbonnel M, Piconne O, Asmar R and Ayoubi J (2011): Pre-eclampsia: pathophysiology, diagnosis, and management. Vascular Health and Risk Management, 7: 467472.

3.Khalil A, Garcia-Mandujano R, Maiz N, Elkhaouli $M$ and Nicolaides KH (2014): Longitudinal changes in uterine artery Doppler and blood pressure and risk of pre-eclampsia. Ultrasound in Obstetrics and Gynecology, 43(5): 541-548.

4.Bhide A, Arulkumaran S, Damania KR and Daftary SN (2015): Aria's practical guide to high-risk pregnancy and delivery a south Asian perspective. In: Hypertensive Disorders in Pregnancy. $4^{\text {th }}$ edition. Haryana, Elsevier. India Private Limited. pp: 185-232.

5. Salomon C, Yee SW, Mitchell MD and Rice GE (2014): The possible role of extravillous trophoblast-derived exosomes on the uterine spiral arterial remodeling under both normal and pathological conditions. BioMed. Research International, http://dx.doi.org/10.1155/2014/693157.

6.Palei A, Spradley FT, Warrington JP, George EM and Granger JP (2013): Pathophysiology of hypertension in preeclampsia: a lesson in integrative physiology. Acta Physiologica, 208(3): 224-233.

7.Lin, S, Leonard D, Co MA, Mukhopadhyay D, Giri B, Perger L, Beeram MR, Kuehl TJ and Uddin MN (2015): Preeclampsia has an adverse impact on maternal and fetal health. Translational Research, 165(4): 449-463.
8.Gupta S, Gupta D and Amin P (2014): $2^{\text {nd }}$ Trimester uterine artery Doppler velocimetry in prediction of preeclampsia. Int. J. Res. Med., 3(4): 120-123.

9.James J, Chamley L and Clark A (2017): Feeding your baby in utero. How the uteroplacental circulation impacts pregnancy. Physiology, 32(3): 234-245.

10. Chakraborty $S$ and Saharan $S$ (2017): Uterine artery Doppler study for the prediction and the severity of the hypertensive disorders during pregnancy. International Journal of Reproduction, Contraception, Obstetrics and Gynecology, 6(7): 2903-2909.

11. Acharya G, Wilsgaard T, Berntsen GK, Maltau JM and Kiserud T (2005): Reference ranges for serial measurements of umbilical artery Doppler indices in the second half of pregnancy. American Journal of Obstetrics and Gynecology, 192(3): 937-944.

12. Melchiorre K, Wormald B, Leslie K, Bhide A and Thilaganathan $B$ (2008): First trimester uterine artery Doppler indices in term and preterm pre-eclampsia. Ultrasound ObstetGynecol., 32: 133-137.

13. Orabona R, Donzelli CM, Falchetti M, Santoro A, Valcamonico A and Frusca T (2016): Placental histological patterns and uterine artery Doppler velocimetry in pregnancies complicated by early or late preeclampsia. Ultrasound in Obstetrics and Gynecology, 47(5): 580-585.

14. Cargill, $Y$, Morin $V$ and Lucie $T$ (2017): No. 223-content of a complete routine second trimester obstetrical ultrasound examination and report. Journal of Obstetrics and Gynaecology Canada, 39(8): 144-149.

15. Polat, I, Gedikbasi A, Kiyak H, Gulac B, Atis A, Goynumer G, Dundar O and Ark C (2015): Double notches: association of uterine artery notch forms with pregnancy outcome and severity of preeclampsia. Hypertension in Pregnancy, 34(1): 90-101.

16. Peixoto $\mathrm{Y}$, Borges $\mathrm{A}$, Caldas $\mathrm{T}$, Barros J, Tonni G, Lima A and Carvalho F (2016): Reference ranges for the uterine arteries Doppler and cervical length measurement at 11-13 (+6) weeks of gestation in a Brazilian population. The Journal of Maternal-Fetal and Neonatal Medicine, 29(18): 2909-2914.

17. Payne Y, Hutcheon B, Ansermino J, Hall D, Bhutta Z, Bhutta S and Li J (2014): A risk prediction model for the assessment and triage of women with hypertensive disorders of pregnancy in low-resourced settings: the 
miniPIERS (Pre-eclampsia Integrated Estimate of RiSk) multi-country prospective cohort study. PLoS Medicine, 11(1): 10015891001594.

18. O'gorman N, Nicolaides $Y$, Kypros $H$ and Liona CY (2016): The use of ultrasound and other markers for early detection of preeclampsia. Women's Health, 12(2): 199207.

19. Kane $S$, Dennis $P$ and Alicia $T$ (2015): Doppler assessment of uterine blood flow in pre-eclampsia: a review. Hypertension in Pregnancy, 34(4): 400-421.

20. Schulman H (2015): Doppler Ultrasound in Pregnancy. In: Cardiac problems in pregnancy, Diagnosis and Management of Maternal and Fetal Heart Disease. Elkayam U, Gleicher N (eds.); Fifth ed., $3^{\text {rd }}$ ed., chapter 46 , Wiley-Liss.

21. Bhattacharyya SK, Kundu $S$ and Kabiraj $S$ (2012): Prediction of preeclampsia by midtrimester uterine artery Doppler velocimetry in high risk and Low risk women. J Obstet Gynaecol India, 62(3): 297-300.

22. Cnossen JS, Morris RK, ter Riet G, Mol BW, van der Post JA, Coomarasamy A, Zwinderman AH, Robson SC, Bindels PJ, Kleijnen J and Khan KS (2008): Use of uterine artery Doppler ultrasonography to predict pre-eclampsia and intrauterine growth restriction: a systematic review and bivariable meta-analysis. Canadian Medical Association Journal, 178: 701-711.

23. Costa F, Cunha $S$ and Berezowski A (2006): Which is the best period to perform uterine artery Doppler in the prediction of pregnancy complications? Radiologia Brasileira, 39.2: 97-102.

24. Katie MG, Robyn A, North, Peter RS, Eliza HY, Chan R, Taylor S, Gustaaf A, Dekker et al. (2009): Patterns Of change in uterine artery doppler studies between 20 and 24 weeks of gestation and pregnancy outcome. The American college of obsteticians and Gynoecologist published, 113(2):332-338.

25. Parretti E, Mealli F, Magrini A, Cioni R, Mecacci F, La Torre P and Mello G (2003): Cross sectional and longitudinal evaluation of uterine artery Doppler velocimetry for the prediction of preeclampsia in normotensive women with specific risk factors Ultrasound Obstet Gynecol., 22: 160-165.

26. Parks W (2015): Placental hypoxia: the lesions of maternal malperfusion. In: Seminars in perinatology. WB Saunders.

27. Afrakhteh M, Moeini A, Taheri MS, Haghighatkhah HR, Fakhri $M$ and Masoom N (2014): Uterine Doppler velocimetry of the uterine arteries in the second and third trimesters for the prediction of gestational outcome. Rev ras GinecolObstet., 36(1):35-9.

28. Nagar T, Sharma D, Choudhary M, Khoiwal S, Nagar RP and Pandita A (2015): The role of Uterine and Umbilical Arterial Doppler in High risk Pregnancy: A Prospective Observational Study from India. Clinical Medicine Insights: Reproductive Health Clin Med Insights Reprod Health, 9:1-5. 